\title{
Identification and Characterization of HD1, a Novel Ofloxacin-Degrading Bacillus Strain
}

\author{
Jing Zhang, Naiqing Sha, Yanhong Li*, Shen Tang, Yuqing Peng and Yao Zhao \\ College of Environmental Science and Engineering, Guilin University of Technology, Guilin, China
}

In recent years, an increasing number of lakes and soils around the world have been polluted by antibiotics, seriously threatening the ecological balance and human health. Currently, there is a lack of understanding of the biodegradation mechanism of typical antibiotics by microorganisms. In this study HD1, a novel Bacillus sp. strain called capable of effectively degrading ofloxacin (OFL), a typical antibiotic with a high detection rate in the environment, was isolated from soil contaminated by OFL. The results of single-factor experiments showed that the optimal conditions for OFL degradation included $30^{\circ} \mathrm{C}, \mathrm{pH} 7.0$, and $10 \mathrm{~g} \mathrm{~L}^{-1} \mathrm{NaCl}$. After 7 days of incubation under aerobic conditions, the degradation efficiency of OFL $\left(5 \mathrm{mg} \mathrm{L}^{-1}\right)$ was about

OPEN ACCESS

Edited by:

Eric D. van Hullebusch, Université de Paris, France

Reviewed by:

Willian Garcia Birolli, Federal University of São Carlos,

Brazil

Eva Camacho, Universidad Pablo de Olavide, Spain

*Correspondence: Yanhong $\mathrm{Li}$ lyh1685@163.com

Specialty section: This article was submitted to Microbiological Chemistry and Geomicrobiology, a section of the journal

Frontiers in Microbiology

Received: 04 December 2021

Accepted: 27 January 2022

Published: 03 March 2022

Citation:

Zhang J, Sha N, Li Y, Tang S,

Peng $Y$ and Zhao $Y$ (2022)

Identification and Characterization of HD1, a Novel Ofloxacin-Degrading

Bacillus Strain.

Front. Microbiol. 13:828922. doi: 10.3389/fmicb.2022.828922 $66.2 \%$. Five degradation products were detected by LC-MS analysis, and it was deduced that the possible degradation pathways of OFL included the oxidation of the piperazine ring, demethylation, hydroxylation, and methoxy cleavage. Metabolomics analysis indicated that key pathways with the highest difference with HD1 metabolites included the phenylalanine, arginine, and proline metabolism pathways. By regulating energy, amino acid metabolism, and carbohydrate metabolism, HD1 could alleviate OFL stress to degrade better. This study explored the degradation mechanism of OFL by HD1 and provides a theoretical basis and technical support for the remediation of OFL-contaminated environments by functional microorganisms.

Keywords: ofloxacin, separation and screening, metabolomics, degradation pathway, Bacillus sp.

\section{INTRODUCTION}

Ofloxacin (OFL), a third-generation fluoroquinolone (FQ) antibiotic, is internationally recognized as an extremely important broad-spectrum antimicrobial agent that is widely used for the clinical treatment of infections and diseases caused by Gram-negative bacteria (Aggio et al., 2010). In recent decades, aqueous environments around the world have increasingly been polluted by FQs (Karthikeyan and Meyer, 2006; Yang et al., 2018). In 11 rivers in Hong Kong, China, OFL was one of the main antibiotics detected (Deng et al., 2018). As a semi-synthetic antibiotic, the stable chemical properties of OFL make it resistant to biodegradation even after decades (Schulz et al., 2019). In addition, due to its high solid-water partition coefficient, it is also easily enriched on the surface of various stable environmental particle carriers, including atmospheric dust, soil particles, and aqueous sediments (Golet et al., 2003; Zhao et al., 2016; Reis et al., 2020). Accumulation and retention of antibiotics in the environment can promote the selection of resistance genes in bacterial populations and affect the dynamics of biological populations followed by entering the human body through the biological chain, which may lead to high risks for ecosystems and human health (Xu et al., 2015; Yang et al., 2018). Therefore, the economical and effective remediation of antibiotic 
pollution of the environment has become a research hotspot (Maki et al., 2006). In fact, compared with physical and chemical remediation methods, antibiotics in most environments are more likely to be decomposed or transformed by microorganisms (Schulz et al., 2019). Microbial remediation of OFL in the environment is one of the most economical and effective methods (Liu et al., 2016). Screening contaminated environments for bacterial strains that are resistant-specific and that are able to efficiently degrade antibiotics is one of the most important means of remediation. The efficient microbial degradation of antibiotics is dependent on environmental factors such as $\mathrm{pH}$, temperature, salt content, and redox conditions (Arikan et al., 2009; Liu et al., 2016). Therefore, the rate of biodegradation of OFL can be improved by screening for strains that efficiently degrade OFL followed by optimizing the environmental conditions of degradation.

Microbial metabolomics studies the complete metabolic characteristics of a biological system by examining the composition and content changes of all small-molecule metabolites before and after a stimulation or disturbance of the biological system in a specific period. It can also be used to identify biomarkers and metabolic pathways (Geng et al., 2016). Due to its high precision, high resolution, high sensitivity, and high throughput, it has been widely used for the detection of microbial metabolites, metabolic pathway research, and microbial classification and identification (Zhang, 2017). Liu et al. (2021) studied the effects of microplastics and dichlorodiphenyltrichloroethane (DDT) on E. coli through metabolomics. The results showed that the toxic effect of DDT was significantly dose-dependent, while the presence of microplastics weakened the response of DDT to the growth and metabolism of $E$. coli. The tricarboxylic acid cycle-related enzyme activity and antioxidant defense-related substances in E. coli also confirmed this mechanism. Li et al. (2020) revealed that biochar combined with plant roots improved bacterial stress to polycyclic aromatic hydrocarbons by metabolomics. Metabolomics has allowed the field of environmental research to make great progress in the past few years and it is considered to be a powerful tool for environmental safety assessment (Zhao et al., 2011). In addition, through the identification of degradation products, it is of great significance to clarify the degradation pathway of pollutants in microorganisms and for elucidating the mechanism of microbial remediation. Durand et al. (2010) used in situ nuclear magnetic resonance and liquid chromatographynuclear magnetic resonance as supplementary tools for LC-MS to determine the metabolic pathway of mesotrione (a new herbicide) degradation by Bacillus sp.

Although progress has been made in the understanding of the environmental fate of antibiotics, little is known about the metabolic potential and degradation mechanism of specific antibiotics by environmental functional microorganisms. The purpose of this study was (1) to screen and isolate high-efficiency OFL degrading bacterial strains from OFL-contaminated soil and identify them by $16 \mathrm{~S}$ rRNA. (2) To explore the optimal conditions for OFL degradation and its possible degradation pathways by HPLC-Q-TOF-MS analysis. (3) The use of metabolomics-based methods to find the differences in metabolites, and then explore the changes in metabolic pathways under OFL stress to determine the degradation mechanism.

\section{MATERIALS AND METHODS}

\section{Main Reagents}

The mixed soil samples were collected from the surrounding area of a livestock and poultry farm in Guilin, Guangxi. All chemical reagents used in the experiments were of analytical grade. Ultrapure water was used throughout. Main media: (1) Inorganic salt medium: $\mathrm{K}_{2} \mathrm{HPO}_{4} 5.8 \mathrm{~g} \mathrm{~L}^{-1}, \mathrm{KH}_{2} \mathrm{PO}_{4} 4.5 \mathrm{~g} \mathrm{~L}^{-1}$, $\left(\mathrm{NH}_{4}\right)_{2} \mathrm{SO}_{4} 2.0 \mathrm{~g} \mathrm{~L}^{-1}, \mathrm{MgCl}_{2} 0.16 \mathrm{~g} \mathrm{~L}^{-1}$, and $\mathrm{CaCl}_{2} 0.02 \mathrm{~g} \mathrm{~L}^{-1}$, adjusted to $\mathrm{pH}$ 7.0. (2) Basic medium: tryptone $10.0 \mathrm{~g} \mathrm{~L}^{-1}$, yeast extract $5.0 \mathrm{~g} \mathrm{~L}^{-1}, \mathrm{NaCl} 10.0 \mathrm{~g} \mathrm{~L}^{-1}, \mathrm{pH}$ 7.5. The medium was sterilized at $121^{\circ} \mathrm{C}$ for $30 \mathrm{~min}$ before use. (3) Phosphate buffer: $\mathrm{NaCl} 8 \mathrm{~g} \mathrm{~L}^{-1}, \mathrm{KCl} 0.2 \mathrm{~g} \mathrm{~L}^{-1}, \mathrm{KH}_{2} \mathrm{PO}_{4} 0.2 \mathrm{~g} \mathrm{~L}^{-1}, \mathrm{pH}$ 7.0. (4) OFL standard stock solution: $1.0 \mathrm{~g}$ OFL was added into $100 \mathrm{~mL}$ deionized water and stirred in the dark with a magnetic stirrer until completely dissolved. The OFL stock solution was stored shielded from light at $4^{\circ} \mathrm{C}$.

\section{Domestication of Bacteria and Isolation and Purification of Strains}

The domestication of OFL-degrading bacteria referred to existing methods (Reis et al., 2014) with slight adjustments. The process was divided into three stages and each stage had a domestication cycle of 15 days. The first stage was as follows: under sterile conditions, soil samples $(3 \mathrm{~g})$ were mixed with $100 \mathrm{~mL}$ inorganic salt medium with yeast extract $\left(1.0 \mathrm{~g} \mathrm{~L}^{-1}\right)$ as the carbon source. The bacteria were cultured in a constant temperature oscillation incubator at $30^{\circ} \mathrm{C}$ and $150 \mathrm{rpm}$ for 15 days in the dark. Add quantitative OFL to make the initial concentration of $5 \mathrm{mg} / \mathrm{Land}$ concentration of OFL was gradually increased to $30 \mathrm{mg} \mathrm{L}^{-1}$ with increments of $5 \mathrm{mg} \mathrm{L}^{-1}$. At the same time, the concentration of yeast extract was decreased gradually from $1.0 \mathrm{~g} \mathrm{~L}^{-1}$, to $0.5,0.3,0.2$, and finally to $0.1 \mathrm{~g} \mathrm{~L}^{-1}$. In each enrichment step, $100 \mathrm{ml}$ of freshly prepared sterilized inorganic salt medium was inoculated with $1 \%$ of the volume of the culture in the previous stage. Enriched bacteria (ECI) were obtained after domestication. In the second stage, the ECI bacteria were inoculated (1\%) into inorganic salt medium and the carbon source in the medium was replaced by a mixture containing amino acids, vitamins, and adenine. The domestication method was the same as in the first stage, and the enriched bacteria obtained were designated ECII. The procedure was repeated in the third stage with an amino acid mixture as carbon source, with the other conditions remaining unchanged, to obtain ECIII. The residual concentrations of OFL in the media at different domestication stages were determined at regular intervals by HPLC and the degradation rates were calculated to screen for bacteria that degrade OFL with high efficiency (Wang, 2020) (see the Supplementary Material for details).

Following acclimation, the activated high-efficiency OFLdegrading bacteria were collected by centrifugation at $2,504 \mathrm{~g}$ for $5 \mathrm{~min}$. The cells were washed 2-3 times with phosphate buffered saline (PBS) and then resuspended in PBS. Dilutions 
$\left(10^{-4} \sim 10^{-8}\right)$ of the bacterial suspension were evenly smeared on the agar solid medium containing OFL. The cells were cultured at $30^{\circ} \mathrm{C}$ for $3 \sim 6$ days until the colonies grew out. Single colonies with different morphological characteristics were selected and further purified by the streak plate method. The procedure was repeated $3 \sim 4$ times until five pure strains (named $\mathrm{HD} 1, \mathrm{HD} 2, \mathrm{HD} 3, \mathrm{HD} 4$, and HD5, respectively) were obtained. These were inoculated into inorganic salt medium containing OFL $\left(1 \mathrm{mg} \mathrm{L}^{-1}\right)$, and their OFL degradation activity was tested after 7 days. The experiment of inorganic salt medium containing OFL without bacteria was designed as the control to eliminate the interference of OFL spontaneous degradation.

\section{Morphological Observation of Strains and Homology Analysis of 16S rDNA Sequences}

The morphology of the strains was characterized by scanning electron microscopy (SEM). The cells cultured for more than $6 \mathrm{~h}$ were removed from the 24-well plate, washed three times with PBS, and fixed with $2.5 \%$ glutaraldehyde for $24 \mathrm{~h}$. Gradient dehydration with ethanol was carried out at subsequent concentrations of $30,50,70,80,90$, and $100 \%$ ethanol for $10 \mathrm{~min}$ each, followed by freeze-drying for $8 \mathrm{~h}$. The cell mounting pieces were fixed to the sample table with conductive adhesive for gold spraying and the morphology of the cells was observed by SEM (Lu et al., 2018).

Genomic DNA was extracted using the OMEGA genomic DNA extraction kit. Next, $16 \mathrm{~S}$ rDNA fragments were PCRamplified with universal primers 27F (AgAgTTTgATCCTg CTCAg) and 1492R (TACgg(C/T)TACCTTgTTACgACTT). PCR reaction mix $(30 \mu \mathrm{L}): 2 \times$ PCR Mix $15 \mu \mathrm{L}$, DNA $1 \mu \mathrm{L}$, upstream primer $(10 \mathrm{mM}) 1 \mu \mathrm{L}$, downstream primer $(10 \mathrm{mM}) 1 \mu \mathrm{L}$, $\mathrm{ddH}_{2} \mathrm{O} 12 \mu \mathrm{L}$. Reaction conditions: $95^{\circ} \mathrm{C} 5 \mathrm{~min}, 94^{\circ} \mathrm{C} 45 \mathrm{~s}$, $55^{\circ} \mathrm{C} 45 \mathrm{~s}, 72^{\circ} \mathrm{C} 1 \mathrm{~min} 15 \mathrm{~s}, 32$ cycles, $72^{\circ} \mathrm{C} 10 \mathrm{~min}$. After the reaction was completed, the size and specificity of the amplified fragments were verified by $1 \%$ agarose gel electrophoresis and photographed using a gel imaging system. The PCR amplification products were purified and sequenced by Beijing Orwellson Biotechnology Co., Ltd. The $16 \mathrm{~S}$ rDNA sequencing results of the obtained strains were analyzed using BLAST, and the related sequences with high homology were selected for relationship analysis. A phylogenetic tree was constructed by the neighbor method of MEGA5 software.

\section{Activity of Ofloxacin-Degrading Bacteria}

Strain HD1 was inoculated (1\%) into inorganic salt medium $(\mathrm{pH}$ 7.0) containing OFL $\left(5 \mathrm{mg} \mathrm{L}^{-1}\right)$. The effects of temperature (15, $25,30,35$, and $\left.45^{\circ} \mathrm{C}\right), \mathrm{pH}(4,5,6,7,8,9$, and 10) and $\mathrm{NaCl}$ concentration $\left(0,5,10,15\right.$, and $\left.20 \mathrm{mg} \mathrm{L}^{-1}\right)$ on the degradation of OFL by HD1 were investigated. Three groups of controls were set in the experiment.

\section{Sample Preparation and Mass Spectrometry Analysis}

The supernatant of the inorganic salt medium was filtered using a $0.22 \mu \mathrm{m}$ filter membrane, and the filtrate was analyzed by high-resolution mass spectrometry (HPLC-QTOF-MS). The molecular weight of the intermediate product was determined, and the material structure was assessed by analyzing the molecular weight of the intermediate product in the mass spectrum.

Degradation products were analyzed using LC-MS or LC-QTOF-MS. The high-resolution mass spectrometer was equipped with an electrospray ion source (ESI) ion source and a quadrupole flight device. The analysis was carried out in the negative ion mode with the scanning mode of $1 / 2$ MS $100 \sim 1,000$. The sample injection volume was $20 \mu \mathrm{L}$, and the flow rate was $0.3 \mathrm{ml}$ $\min ^{-1}$. The chromatographic column was Agilent Extend-C18 $(2.1 \mathrm{~mm} \times 50 \mathrm{~mm}, 1.7 \mu \mathrm{m})$. The mobile phase was $0.1 \%$ formic acid solution (mobile phase A) and acetonitrile (mobile phase B). Gradient elution was as follows: $10 \%$ mobile phase B: $1 \mathrm{~min}$. The mobile phase B increased to $90 \%$ within $3 \mathrm{~min}$ and this was maintained for $12 \mathrm{~min}$. Next, the mobile phase B decreased to $10 \%$ within $3 \mathrm{~min}$. The ion source gas temperature was $350^{\circ} \mathrm{C}$, the ion gas concentration was $12 \mathrm{~mL} / \mathrm{min}$, the ion spray voltage was $4,000 \mathrm{~V}$, the first-order mass spectrometry collision energy is $175 \mathrm{~V}$, and the second-order mass spectrometry collision energy is $185 \mathrm{~V}$.

The degradation products of OFL were analyzed by HPLCQ-TOF-MS. Under positive ion mode, after 7 days of culture, the bacterial liquid was injected into the mass spectrometry by injection pump at the speed of $0.3 \mathrm{ml} \mathrm{min}^{-1}$. The response intensity of ESI to OFL molecular ions was investigated in positive and negative ion mode by full scan mode, and the parent ion was determined.

\section{Sampling and Extraction of Metabolites}

A suspension of the HD1 strain $(1 \mathrm{~mL})$ was inoculated into $100 \mathrm{~mL} \mathrm{LB}$ liquid medium and cultured at $35^{\circ} \mathrm{C}$ for $24 \mathrm{~h}$ at $150 \mathrm{r}$ $\min ^{-1}$. In the experimental group, the OFL stock solution was added into $100 \mathrm{~mL} \mathrm{LB}$ medium, at final concentrations of OFL of 10 and $5 \mathrm{mg} \mathrm{L}^{-1}$ recorded as group A and group B, respectively, with five parallel samples in each group, denoted as A1 A5 and $\mathrm{B} 1 \sim \mathrm{B} 5$. The control group lacked OFL, marked as C1 $\sim \mathrm{C} 5$. After $24 \mathrm{~h}$ of culture, the appropriate amount of bacterial liquid was collected and placed in a sterile centrifuge tube followed by centrifugation at $2,504 \mathrm{~g}, 4^{\circ} \mathrm{C}$ for $3 \mathrm{~min}$. The bacteria were resuspended in pre-cooled PBS, centrifuged for $3 \mathrm{~min}$ at 2,504 $\mathrm{g}$ and $4^{\circ} \mathrm{C}$, and then frozen on dry ice.

Extraction of metabolites was conducted according to Sangster et al. (2006) and Aggio et al. (2010). Microbial cell metabolomics by methyl chloroformate derivatization-gas chromatographymass spectrometry was as follows: samples (60 mg) were transferred to a $2 \mathrm{~mL}$ centrifuge tube and $500 \mu \mathrm{L}$ methanol $\left(-20^{\circ} \mathrm{C}\right)$ were added as well as $500 \mu \mathrm{L}$ Double distilled water $\left(\mathrm{ddH}_{2} \mathrm{O}\right)\left(4^{\circ} \mathrm{C}\right)$, and glass beads $(100 \mathrm{mg})$, and vortexed for $30 \mathrm{~s}$. The centrifuge tube was placed in an adapter, immersed in liquid nitrogen for $5 \mathrm{~min}$, and then thawed at room temperature. Next, the centrifuge tube was replaced in the adapter, placed in a tissue grinder, and oscillated at $70 \mathrm{~Hz}$ for $2 \mathrm{~min}$. This procedure was repeated twice. The sample was centrifuged at 7,512 $\mathrm{g}$ for $10 \mathrm{~min}$ at $4^{\circ} \mathrm{C}$. The supernatant was concentrated, and dried. The sample was dissolved in $300 \mu \mathrm{L}$ of a 2-chlorophenylalanine (4 ppm) 
methanol solution $\left(1: 1,4^{\circ} \mathrm{C}\right)$ and filtered through a $0.22 \mu \mathrm{m}$ membrane. The sample was then analyzed by LC-MS. Aliquots $(20 \mu \mathrm{L})$ were used as quality control (QC) samples, and the remaining samples were analyzed by LC-MS.

Chromatographic conditions were as follows (Holmes et al., 2010): gas chromatography was performed on a Thermo Vanquish instrument, equipped with an ACQUITY UPLC ${ }^{\circledR}$ HSS T3 $1.8 \mu \mathrm{m}(2.1 \mathrm{~mm} \times 150 \mathrm{~mm})$ chromatographic column. The temperature of the automatic sampler was set to $8^{\circ} \mathrm{C}$, the flow rate was $0.25 \mathrm{ml} \mathrm{min}{ }^{-1}$, the column temperature was $40^{\circ} \mathrm{C}$, and the injection volume was $2 \mu \mathrm{L}$ for gradient elution. The mobile phase was $0.1 \%$ formic acid aqueous solution (A1)- $-1 \%$ formic acid acetonitrile (B1). The negative ion was a $5 \mathrm{mmol}$ $\mathrm{L}^{-1}$ ammonium formate aqueous solution (A2) and acetonitrile (B2). The gradient elution program was as follows: $0 \sim 1 \mathrm{~min}$, 2\% B2/B1. $1 \sim 9 \min , 2 \sim 50 \%$ B2/B1. $9 \sim 12 \min , 50 \sim 98 \%$ B2/B1. $12 \sim 13.5 \mathrm{~min}, 98 \%$ B2/B1. $13.5 \sim 14 \min , 98 \sim 2 \%$ B2/B1. $14 \sim 20 \mathrm{~min}, 2 \% \mathrm{~B} 1$ - positive mode $(4 \sim 17 \mathrm{~min}, 2 \%$ B2-negative mode).

\section{RESULTS AND DISCUSSION}

\section{Isolation and Identification of Ofloxacin-Degrading Bacteria}

The activated high-efficiency OFL-degrading bacterium after domestication was streaked on an agar plate, and single colonies with good growth and consistent morphology were purified by continuous streaking. Five strains of OFL-resistant bacteria were obtained after $3 \sim 4$ purification cycles, which were labeled $\mathrm{HD} 1, \mathrm{HD} 2, \mathrm{HD} 3, \mathrm{HD} 4$, and $\mathrm{HD} 5$, respectively. The colony morphologies of the five strains are shown in Figure $\mathbf{1}$ and the
16S rDNA gene sequences were obtained and compared with GeneBank sequences. The results of the comparison are shown in Supplementary Table 1.

The five OFL-degrading strains were inoculated into the inorganic salt medium ( $\mathrm{pH} 7.0)$ containing OFL $\left(5 \mathrm{mg} \mathrm{L}^{-1}\right)$, grown at $30^{\circ} \mathrm{C}$ and tested for OFL degradation activity within 7 days. We found that the OFL degradation efficiency of HD1 was $66.2 \%$, while that of the other 4 strains was $28.4,61.9,45.6$, and $58.4 \%$, respectively. And the degradation rate of the control group was 2.16\% (Supplementary Figure 1). The SEM images showed that the cells of strain HD1 were rod-shaped, flagellafree, wrinkled, and convex in the middle, while the surface was rough and glossy. The dimensions of the cells were 1.2$1.3 \mu \mathrm{m} \times 0.8-1.0 \mu \mathrm{m}$ (Figure 2A). The strain was identified as gram-positive and facultative anaerobic following the protocol described by experimental method of "Common Bacterial System Identification Manual” and "Bergey's Manual of Determinative Bacteriology" with slight adjustments (Hort et al., 1994; Dong and Cai, 1999). The 16S rRNA amplicon sequencing results revealed a total of 1,404 bases with a homology between HD1 and Bacillus haynesii of $99.575 \%$. The location of HD1 in a phylogenetic tree based on 16S rDNA sequences is shown in Figure 2B. Previous studies have found that Bacillus strains can degrade norfloxacin, a different fluoroquinolone antibiotic, effectively, mainly through the structures of the pyrazine ring and the quinolone ring (Liyanage and Manage, 2018).

\section{Effect of $\mathrm{pH}$, Temperature, and $\mathrm{NaCl}$ Concentration on the Degradation Rate of Ofloxacin by Strain HD1}

Environmental conditions such as temperature and $\mathrm{pH}$ value can significantly affect the degradation rate of a variety of

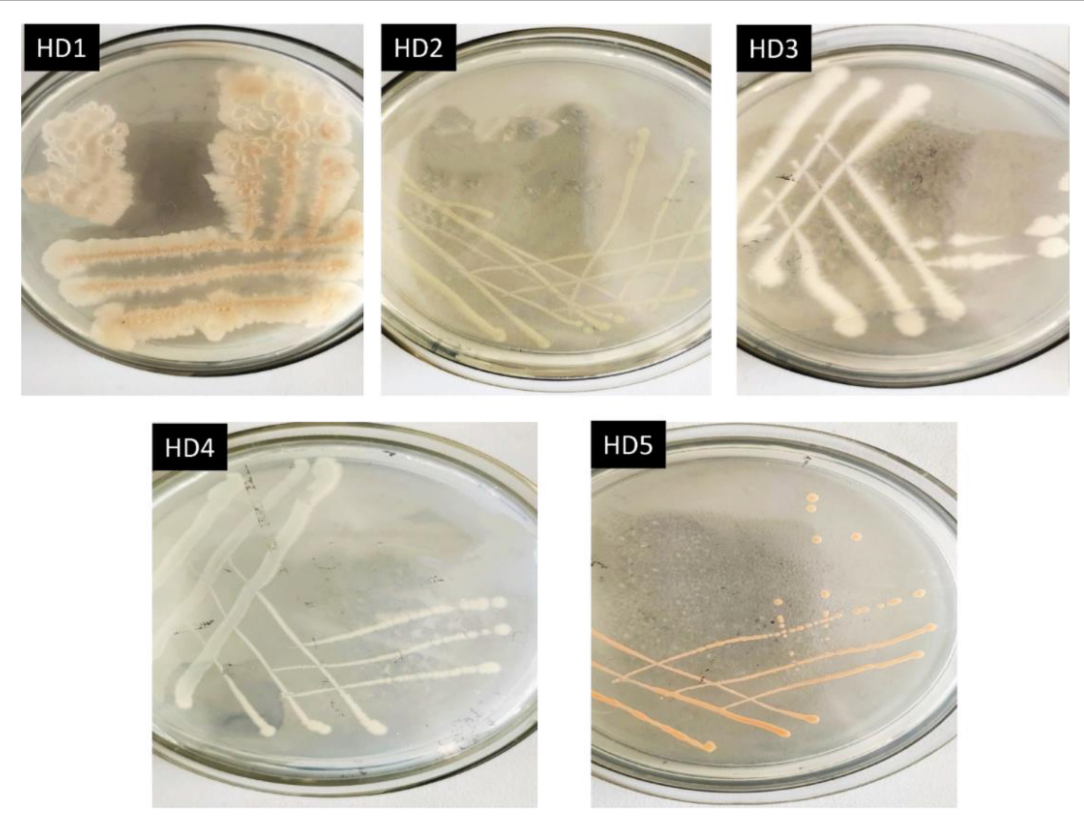

FIGURE 1 | Colony morphologies of 5 OFL-resistant bacterial strains on solid medium. 


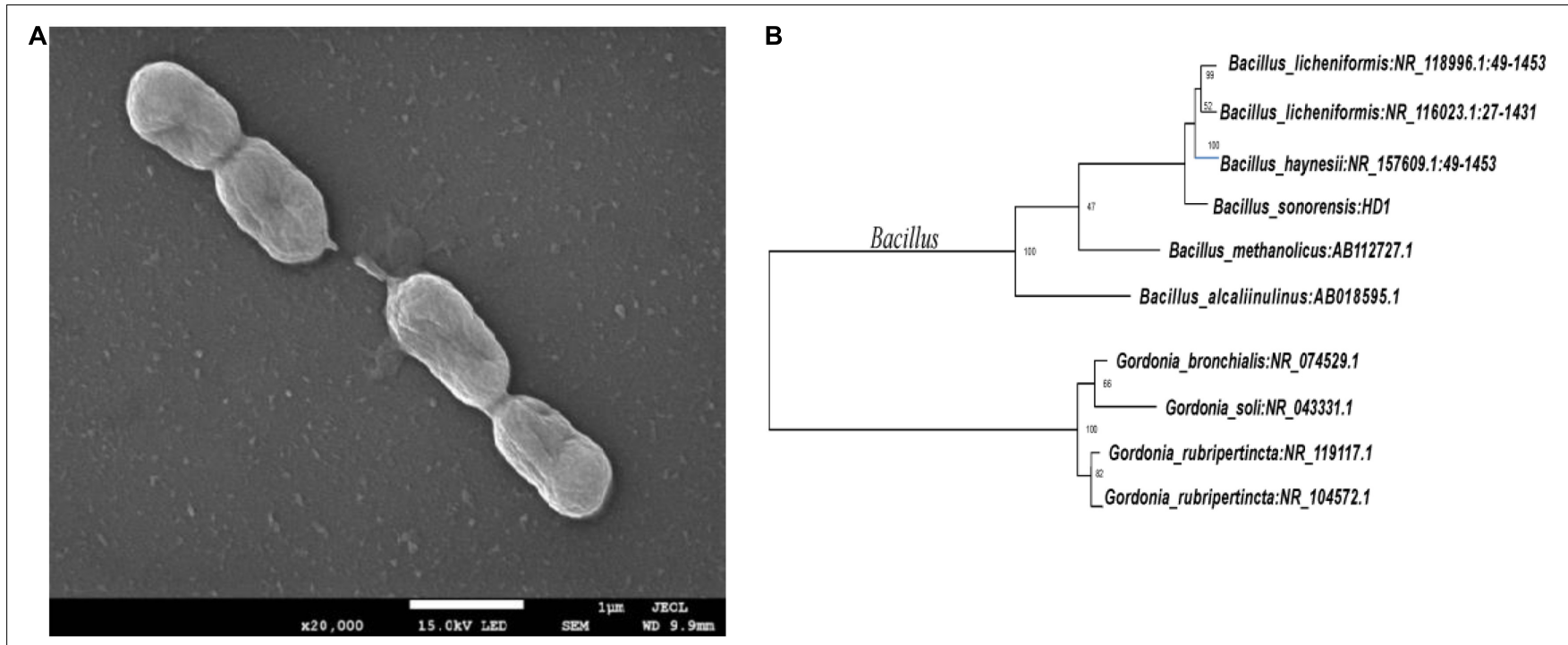

FIGURE 2 | (A) Scanning Electron Microscope image of HD1 and (B) Phylogenetic tree based on 16S rRNA sequence highlighting the phylogenetic position of HD1.
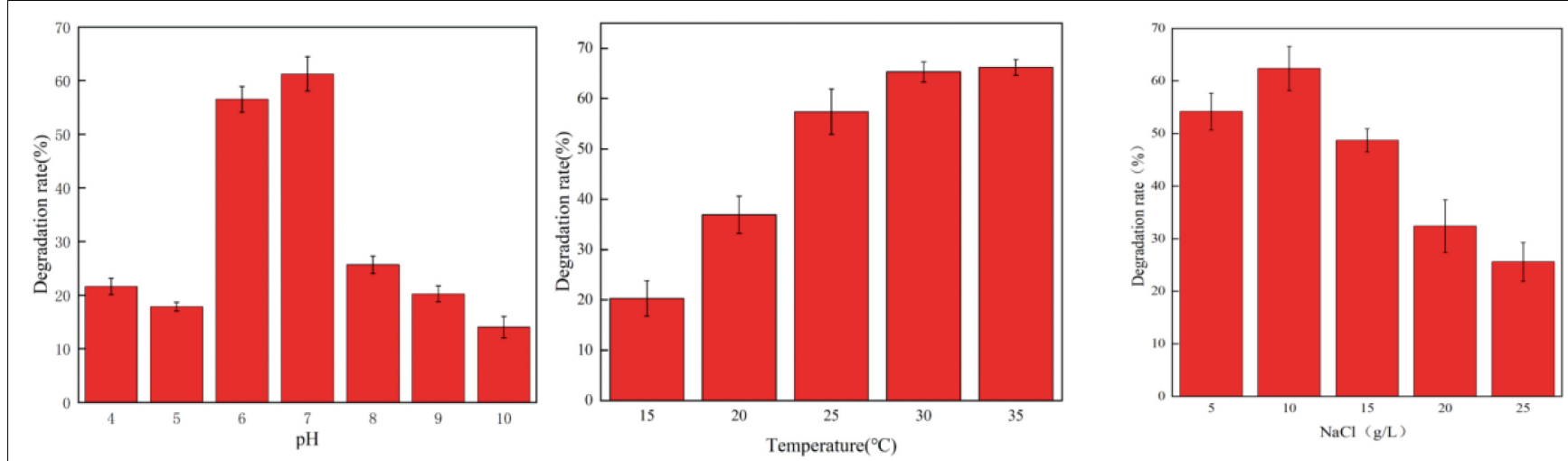

FIGURE 3 | The Effect of different $\mathrm{pH}$ values (left, $30^{\circ} \mathrm{C}, 10 \mathrm{~g} / \mathrm{L} \mathrm{NaCl}$ ), temperatures (middle, $\mathrm{PH}=7,10 \mathrm{~g} / \mathrm{L} \mathrm{NaCl}$ ), and NaCl concentrations (right, $30^{\circ} \mathrm{C}, \mathrm{PH}=7$ ) on the degradation rate of OFL by strain HD1.

antibiotics such as chlortetracycline (CT), oxytetracycline (OTC), and tetracycline (TET) (Feng et al., 2013; Böttger et al., 2015). In this study, the effects of $\mathrm{pH}$, temperature, and $\mathrm{NaCl}$ concentration on the degradation of OFL by HD1 were investigated under different environmental conditions (Figure 3). It was found that when $\mathrm{pH}$ was in the range of $6.0 \sim 7.0$, the strain could carry out normal growth and metabolism, and its ability to degrade OFL was also relatively stable. However, below $\mathrm{pH} 6.0$ or above $\mathrm{pH} 7.0$, the ability of HD1 to degrade OFL by HD1 had significantly worsened. When the temperature was $25 \sim 35^{\circ} \mathrm{C}$, the strain metabolized well, and the degradation effect of OFL was good at $30^{\circ} \mathrm{C}$. When the temperature was $\leq 15^{\circ} \mathrm{C}$, the degradation efficiency of OFL was the lowest, which may be due to the stagnation of growth and metabolism of strains at low temperatures. When the salt concentration range was $5 \sim 15 \mathrm{~g}$ $\mathrm{L}^{-1}$, the growth and metabolism of the strain were normal, and the optimal salinity for degrading OFL was $10 \mathrm{~g} \mathrm{~L}^{-1}$. As studies have shown, high concentrations of salt in river water and activated sludge inhibit the biodegradation of sulfonamides (Li and Zhang, 2010; Adamek et al., 2016). Studies have also found that in pure fresh water (salinity of $0 \%$ ) and pure sea water (salinity of $34.82 \%$ ), the conversion rate of Vibrio vulgaris L2-2 to a variety of sulfonamide antibiotics is low (Wang, 2021). We infer that too high or too low salinity will affect the osmotic pressure of bacteria, resulting in slow growth and metabolism of strains, and the degradation of OFL will also decrease.

\section{Analysis of Degradation Products and Pathway Inference}

Current studies have shown that the degradation mechanisms of FQs mainly include the following pathways: piperazine ring cracking, demethylation, hydroxylation, and N-acetylation. However, the specific biodegradation pathway of OFL remains unclear. Wang et al. (2012) used HPLC-MS to identify the degradation products of levofloxacin due to damage by 


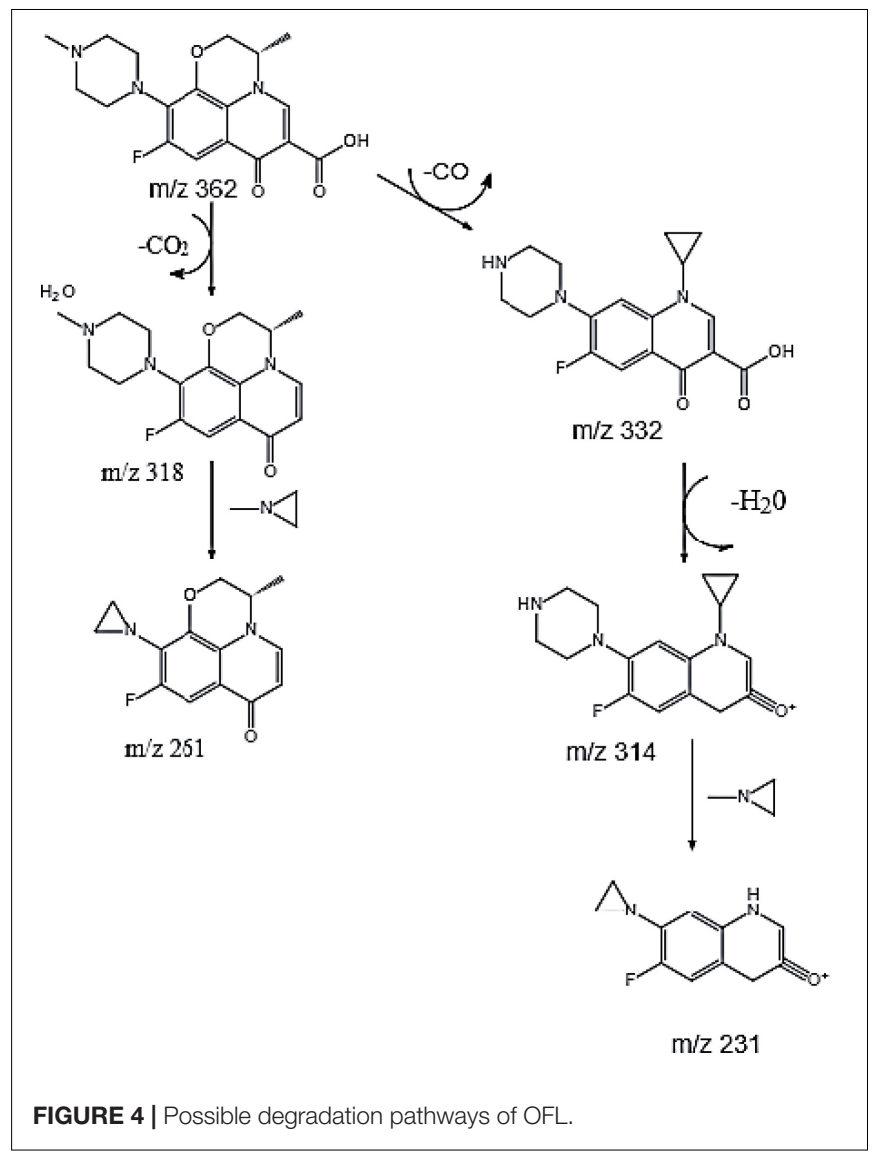

acid, oxidation, and light. Four intermediate degradation products were obtained with mass-to-core ratios of 328.1, 378.1, 348.2, and 378, respectively. Golet et al. (2003) studied the degradation of norfloxacin by the norfloxacin-degrading strain Staphylococcus caprae and found four degradation products produced by the following pathways: breaking and oxidation of the piperazine ring, replacement of the fluorine atom by a hydroxyl group or benzene ring hydrogen. In this experiment, molecular ion peaks with high response intensity were observed in the mass spectrum (Supplementary Figure 2). According to the ion characteristic peak at $\mathrm{m} / \mathrm{z}=362.1519$ $[\mathrm{M}+\mathrm{H}]^{+}$and its molecular weight of 361.1529 , the substance was determined as OFL. The characteristic peaks of four ion fragments in the secondary mass spectrum were $\mathrm{m} / \mathrm{z}=261.1033$, $318.1612,314.1299$, and 332.1401, respectively. We speculated that the molecular formulae of the main degradation products during the degradation of OFL by strain $\mathrm{HD} 1$ are $\mathrm{C}_{17} \mathrm{H}_{21} \mathrm{FN}_{3} \mathrm{O}_{2}, \mathrm{C}_{14} \mathrm{H}_{14} \mathrm{FN}_{2} \mathrm{O}_{2}, \mathrm{C}_{17} \mathrm{H}_{21} \mathrm{FN}_{3} \mathrm{O}_{3}, \mathrm{C}_{17} \mathrm{H}_{19} \mathrm{FN}_{3} \mathrm{O}_{2}$, and $\mathrm{C}_{12} \mathrm{H}_{8} \mathrm{FN}_{2} \mathrm{O}_{2}$, respectively, and the molecular structure of OFL is shown in Supplementary Table 2.

Based on the above analysis, we speculated that there are two parallel pathways for the degradation of OFL by the HD1 strain (Figure 4). In the first possible pathway, the carbonyl group of OFL was removed by an inducible enzyme to form the product $\mathrm{C}_{17} \mathrm{H}_{21} \mathrm{FN}_{3} \mathrm{O}_{2}$. Then, the carbon-nitrogen bond on the piperazine ring was oxidized to form an 1-Methylethylenimine, and finally the degradation product $\mathrm{C}_{14} \mathrm{H}_{14} \mathrm{FN}_{2} \mathrm{O}_{2}$. In the second possible pathway OFL lost a $\mathrm{C}$ atom and $\mathrm{C}=\mathrm{O}$ bond and the methyl group and the methoxy group of the benzene ring on the piperazine ring were broken. Following the ringopening, $\mathrm{C}_{17} \mathrm{H}_{21} \mathrm{FN}_{3} \mathrm{O}_{3}$ was rearranged. Previous studies on the degradation of ciprofloxacin (CIP) found that CIP degradation mainly occurred on two functional groups: the piperazine group and quinolone part, and the product was also detected in the mass spectrometry ion fragments (Hongguang et al., 2016). Then an $\mathrm{H}_{2} \mathrm{O}$ molecule was removed from $\mathrm{C}_{17} \mathrm{H}_{21} \mathrm{FN}_{3} \mathrm{O}_{3}$ to form $\mathrm{C}_{17} \mathrm{H}_{19} \mathrm{FN}_{3} \mathrm{O}_{2}$. Finally, the $\mathrm{C}-\mathrm{N}$ bond on the benzene ring was broken, the amino ring ethyl was removed, and the piperazine ring was oxidized to form $\mathrm{C}_{12} \mathrm{H}_{8} \mathrm{FN}_{2} \mathrm{O}_{2}$. This product was also detected in the degradation products of norfloxacin and CIP by a white-rot fungus (Prieto et al., 2011). Based on this, we inferred that the degradation pathways of OFL include piperazine ring oxidation, demethylation, hydroxylation, and methoxy breakage.
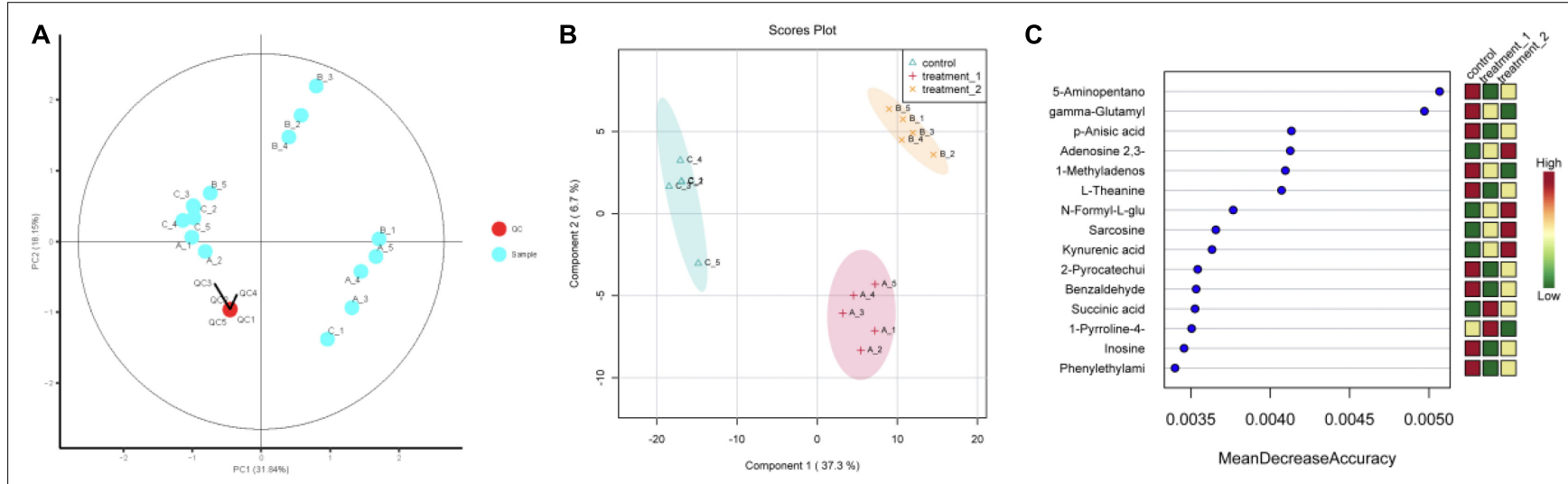

FIGURE 5 | (A) Quality control sample PCA chart; (B) PLS-DA point cloud; (C) variable importance in project corresponding to the PLS-DA. The abscissa of (C) (Mean Decrease Accuracy) measures the importance of a metabolite in random forests. The right figure is the heat map of the content of metabolites in the two groups in 15.) Treatment 1 corresponds to group A (OFL concentration is $10 \mathrm{mg} / \mathrm{L}$ ); treatment 2 corresponds to group $B$ (OFL concentration is $5 \mathrm{mg} / \mathrm{L})$; Control does not add OFL. 


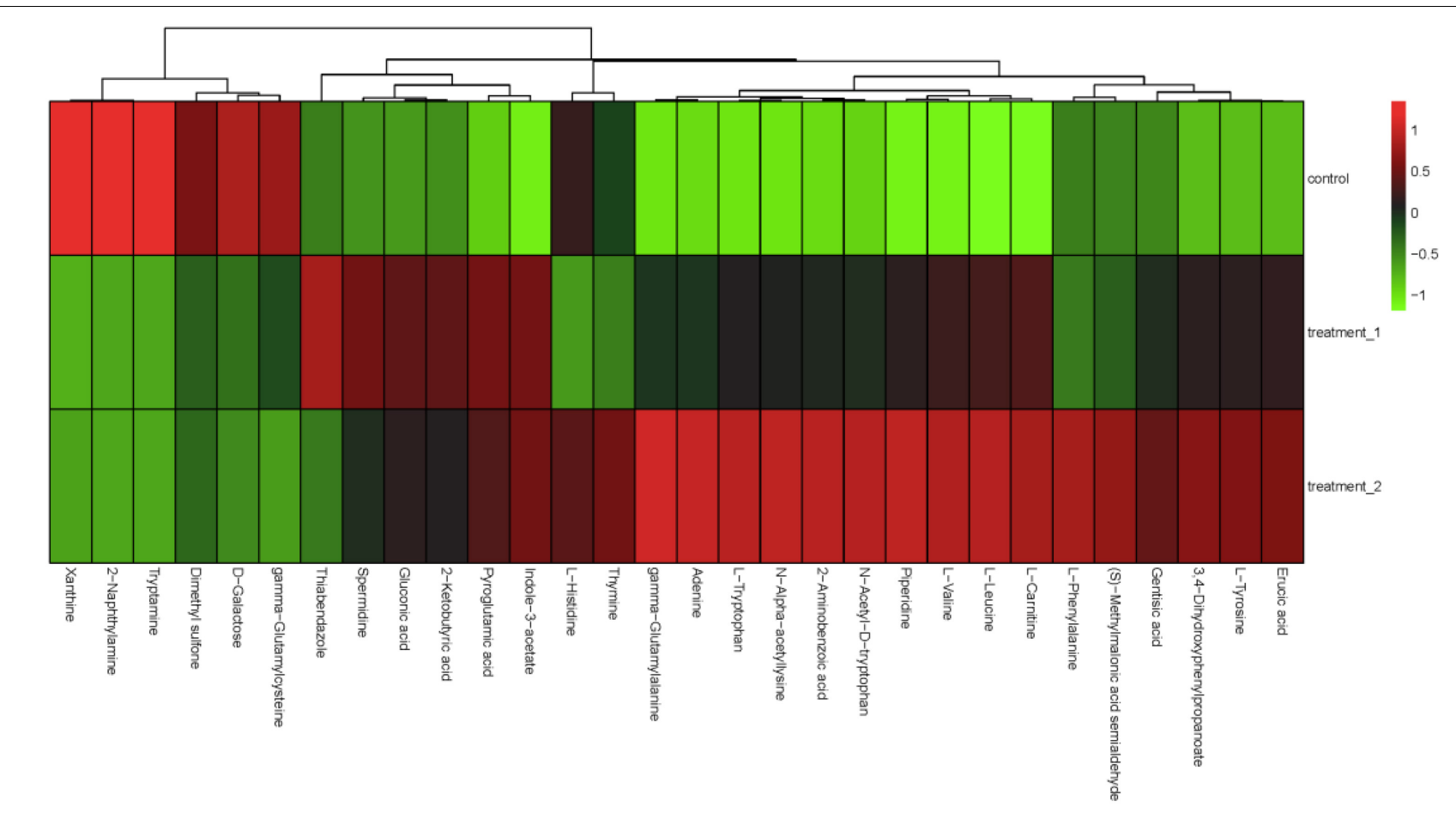

FIGURE 6 | Hierarchical cluster analysis heat map. The concentration of $10 \mathrm{mg} / \mathrm{L}$ OFL is treatment 1 ; and the concentration of $5 \mathrm{mg} / \mathrm{L}$ OFL is treatment 2; Control does not add OFL.
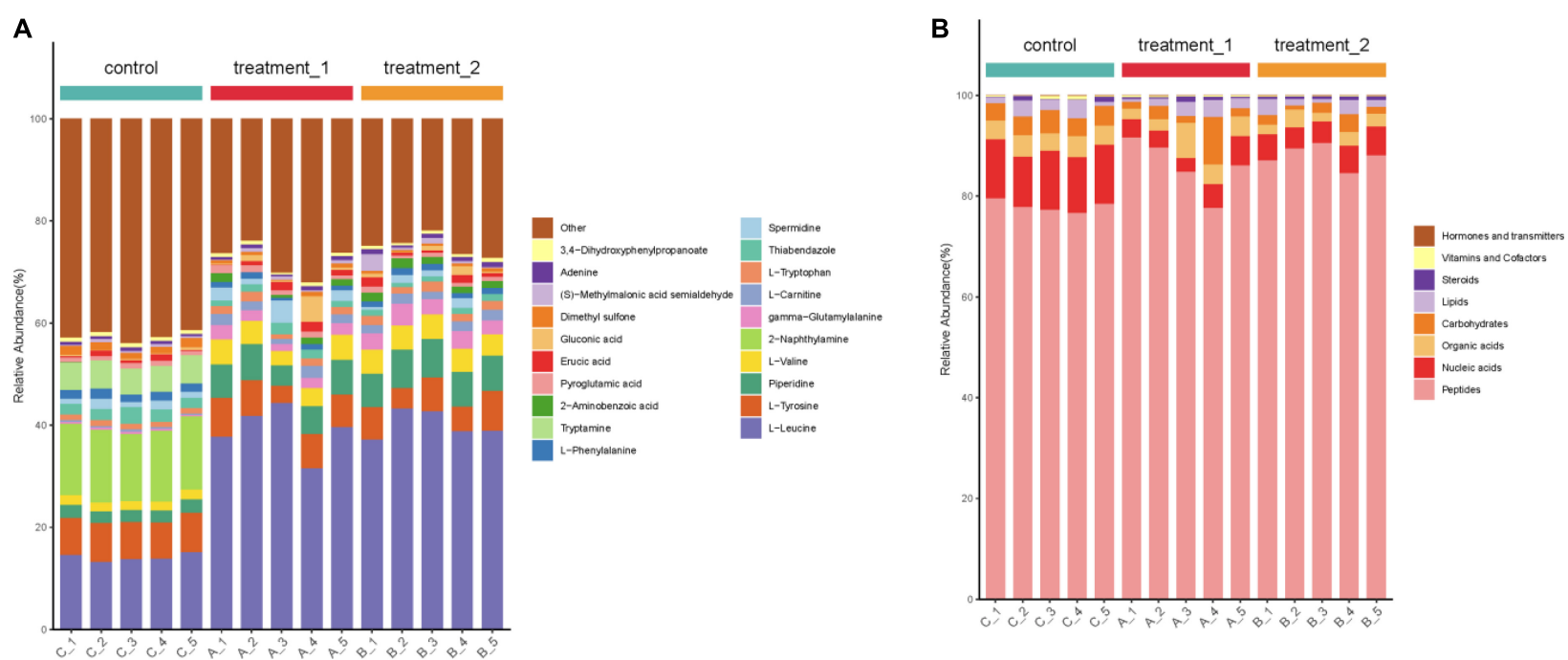

FIGURE 7 | (A) Stacked column chart indicating relative abundance of metabolites or (B) groups of metabolites. Shown in the left panel is the percentage accumulation of the top 20 metabolites upon treatment with OFL at two different concentrations compared with the control treatment. The right panel shows the relative abundance of metabolites according to biological roles. The concentration of $10 \mathrm{mg} / \mathrm{L}$ OFL is treatment 1 ; and the concentration of $5 \mathrm{mg} / \mathrm{L}$ OFL is treatment 2; Control does not add OFL.

\section{Metabolomics Analysis of HD1 Under Ofloxacin Stress}

The QC-RFSC algorithm of the Stat Target package of R language was used for QC to correct the signal peak of each sample and record the correction effect. As shown in Figure 5A, the
QC sample points overlapped and all samples were located in a $95 \%$ confidence interval, which strongly suggested that the experimental data are highly reliable. Partial least squares discriminant analysis (PLS-DA) projected the predicted and observed variables into a new space, as shown in Figure 5B, 


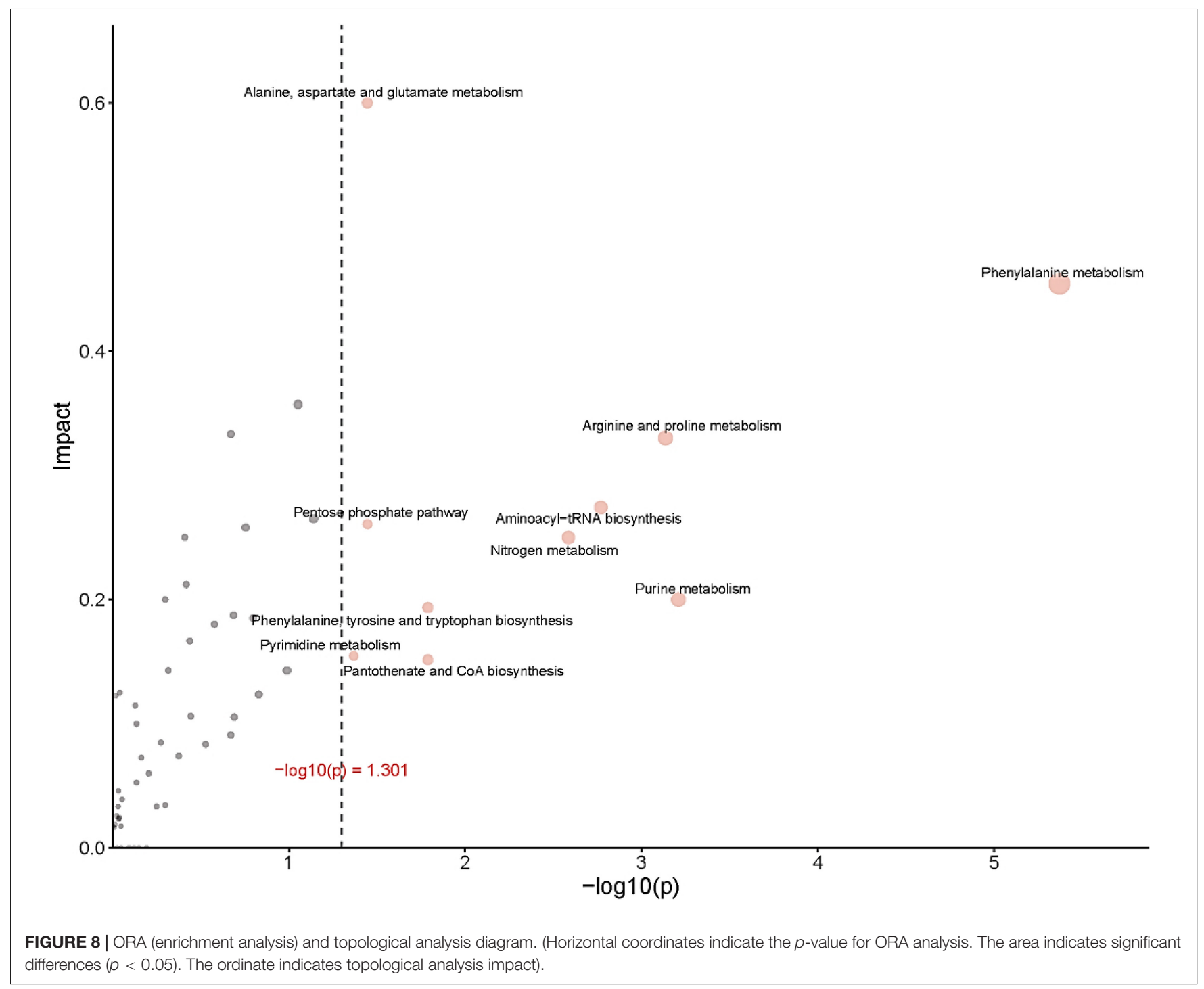

indicating that different OFL concentrations led to significant changes in metabolite patterns. Therefore, we speculated that strain HD1 adapted to different OFL concentrations with different metabolic response mechanisms. Some evidences of bacterial metabolomics regulation indicate that the high abundance of bacterial endogenous metabolites is closely related to the resistance of bacteria to antibiotics. Such as indole, nitric oxide, hydrogen sulfide, glucose, and amino acids can change the metabolic environment of a variety of bacterial cells and antibiotic sensitivity (Gusarov et al., 2009; Allison et al., 2011; Shatalin et al., 2011). In this study, the strongest positively correlated metabolites according to random forest classification were 5-aminopentano, gamma-glutamyl, p-anisic acid, 1-methyladenosine, and L-theanine, while adenosine 2,3 was negatively correlated with OFL concentrations (Figure 5C). Therefore, the significant changes in these metabolites may also indicate that they may be a key biomarker for the resistance of strain HD-1 to OFL. These results prompted us to explore whether the suppressed level of adenosine 2,3 is a useful biomarker and if adenosine 2,3 could act as a modulator for OFL-resistant. The thermogram of metabolite changes showed that amino acid metabolites (such as L-phenylalanine and Ltryptophan) were responsible for the changes in metabolic patterns, which might be due to the significant up-regulation of these metabolites upon OFL treatment (Figure 6). Since Ltryptophan is often hidden inside the protein, its indole ring is very sensitive to the environment, so it can be used as an indicator of protein structural changes (Chen and Barkley, 1998; Zhang et al., 2015). Therefore, it can also be inferred that OFL treatment changed the protein structure of the strain.

According to the percentage accumulation column diagram of metabolites (Figure 7) the metabolite content of strain HD1 was significantly different in OFL stress environments compared with the absence of OFL. Under OFL stress, the content of L-leucine and piperidine increased significantly while the content of Tryptamine, 2-naphthylamine decreased compared with the control. The significant changes in metabolite levels indicated that OFL stress may induce changes in multiple 
metabolic pathways in HD1. For example, the increased amino acid (L-leucine) content may be the result of increased catabolism generated by energy. Under external pressure, proteins are decomposed to release free amino acids or peptides (Fu et al., 2019). This was confirmed by Figure 7 (right panel), showing that the relative abundance of peptides metabolized by HD1 in the presence of OFL was higher than that of the control group. The decreased relative abundance of nucleic acids and carbohydrates may indicate that OFL stimulated glycolysis and nucleotide metabolism in HD1 and increased microbial metabolic activity accelerated intracellular carbohydrate decomposition and energy consumption to adapt to environmental disturbances ( $\mathrm{Hu}$ et al., 2020). Microbial metabolism is a complex regulatory network involving multiple genes and proteins. Microorganisms can adjust their metabolic processes to cope with environmental pressure to improve their chances of survival (Kosová et al., 2018).

Figure $\mathbf{8}$ provides an over-representation (enrichment) analysis (ORA) of the pathways that were affected by OFL treatment, indicating the pathway impact value $[-\log (\mathrm{p})]$ determined by metabolic pathway enrichment analysis and metabolic pathway topology analysis. The pathway analysis, using MetaboAnalyst, showed that the observed metabolic disturbance indicated the effects on various pathways, including phenylalanine metabolism and arginine and proline metabolism, alanine, aspartate and glutamate metabolism, pentose phosphate pathway, nitrogen metabolism, purine metabolism, and aminoacyl-tRNA biosynthesis, further indicating that the effects on these pathways may affect the energy metabolism, amino acid metabolism, and carbohydrate metabolism of HD1. Recent studies have reached similar conclusions. Researchers have found that the abundance of $\mathrm{L}$-aspartic acid is related to the antibiotic resistance of $\mathrm{A}$. hydrophila. $\mathrm{L}$-aspartic acid is inhibited in the metabolism of strains, and this study shows that by regulating the metabolic pathway of L-aspartic acid, Change the sensitivity of bacteria to antibiotics (Zhao et al., 2018). In addition, the results further showed that phenylalanine, arginine, and proline metabolism pathways were the key pathways in HD1 that were most affected by OFL treatment (Figure 8).

\section{CONCLUSION}

In this work, we isolated a novel Bacillus strain, named HD-1, that effectively degraded OFL from among high-efficiency degrading bacteria enriched in OFL-contaminated soil. Under optimal conditions $\left(30^{\circ} \mathrm{C}, \mathrm{pH} 7.0,10 \mathrm{~g} \mathrm{~L}^{-1} \mathrm{NaCl}\right)$, the degradation rate

\section{REFERENCES}

Adamek, E., Baran, W., and Sobczak, A. (2016). Assessment of the biodegradability of selected sulfa drugs in two polluted rivers in Poland: effects of seasonal variations, accidental contamination, turbidity and salinity. J. Hazard. Mater. 313, 147-158. doi: 10.1016/j.jhazmat.2016.03.064

Aggio, R. B. M., Villas-Bôas, S. G., Van Houtte, J. R., and Smart, K. F. (2010). Analytical platform for metabolome analysis of microbial cells using methyl chloroformate derivatization followed by gas chromatography-mass spectrometry. Nat. Protoc. 5, 1709-1729. doi: 10.1038/nprot.2010.108 of OFL was $66.2 \%$. We further detected five OFL degradation products by HPLC-MS/MS and proposed two putative OFL degradation pathways in HD1. The main degradation processes involved the oxidation, demethylation, and hydroxylation of the piperazine ring of OFL. Through the analysis and identification of differential metabolites and metabolomics analysis of HD1 under OFL stress, we found that the differences between metabolite levels between normal (non-stressed) HD1 and OFL-stressed HD1 was highest in three key metabolic pathways, suggesting that HD1 could alleviate OFL stress by regulating energy, amino acid metabolism, and carbohydrate metabolism. The results of this study are critical for evaluating the fate of OFL in engineering and natural systems and for designing bioremediation strategies. In addition, this study expands the existing knowledge of microbial degradation in ecosystems affected by OFL pollution and provides a theoretical basis for the application of bioremediation in an environment with high antibiotic levels.

\section{DATA AVAILABILITY STATEMENT}

The original contributions presented in the study are included in the article/Supplementary Material, further inquiries can be directed to the corresponding author/s.

\section{AUTHOR CONTRIBUTIONS}

JZ and NS designed and conducted the experiments. YL and ST compiled and analyzed the output data, designed and wrote the first version of the manuscript, and conceived and supervised the project. YP and YZ managed the funding acquisition. All authors edited and approved the final version of the manuscript.

\section{FUNDING}

This work was financially supported by the National Science Foundation of China (No. 52070050) and the Natural Science Foundation of Guangxi (No. 2020GXNSFAA159017).

\section{SUPPLEMENTARY MATERIAL}

The Supplementary Material for this article can be found online at: https://www.frontiersin.org/articles/10.3389/fmicb. 2022.828922/full\#supplementary-material

Allison, K. R., Brynildsen, M. P., and Collins, J. J. (2011). Metabolite-enabled eradication of bacterial persisters by aminoglycosides. Nature 473, 216-220. doi: 10.1038/nature10069

Arikan, O. A., Mulbry, W., and Rice, C. (2009). Management of antibiotic residues from agricultural sources: use of composting to reduce chlortetracycline residues in beef manure from treated animals. J. Hazard. Mater. 164, 483-489. doi: 10.1016/j.jhazmat.2008. 08.019

Böttger, R., Schaller, J., Lintow, S., and Gert Dudel, E. (2015). Aquatic degradation of Cryl $\mathrm{Ab}$ protein and decomposition dynamics of transgenic corn leaves under 
controlled conditions. Ecotox. Environ. Saf. 113, 454-459. doi: 10.1016/j.ecoenv. 2014.12.034

Chen, Y., and Barkley, M. D. (1998). Toward understanding tryptophan fluorescence in proteins. Biochemistry 37, 9976-9982. doi: 10.1021/bi980274n

Deng, W., Li, N., and Ying, G. (2018). Antibiotic distribution, risk assessment, and microbial diversity in river water and sediment in Hong Kong. Environ. Geochem. Health 40, 2191-2203. doi: 10.1007/s10653-018-0092-1

Dong, X., and Cai, M. (1999). Handbook for the Identification of Common Bacteria. Beijing: Science Press, 353-365.

Durand, S., Sancelme, M., Besse-Hoggan, P., and Combourieu, B. (2010). Biodegradation pathway of mesotrione: complementarities of NMR, LC-NMR and LC-MS for qualitative and quantitative metabolic profiling. Chemosphere 81, 372-380. doi: 10.1016/j.chemosphere.2010.07.017

Feng, F., Xu,X., Cheng, Q., and Han, Y. (2013). Degradation characteristics of tetracycline hydrochloride by Trichosporon mycotoxinivorans XPY-10. Chinese J. Environ. Eng. 7, 4779-4785.

Fu, B., Chen, L., Cai, T., Yang, Q., and Ding, D. (2017). Isolation and characterization of norfloxacin-degrading bacterium strain NOR-36. Acta Sci. Circumstantiae 37, 576-584. doi: 10.13671/j.hjkxxb.2016.0245

Fu, J., Gong, Z., and Kelly, B. C. (2019). Metabolomic profiling of zebrafish (Danio rerio) embryos exposed to the antibacterial agent triclosan. Environ. Toxicol. Chem. 38, 240-249. doi: 10.1002/etc.4292

Geng, N., Zhang, H., Wang, F., Ren, X., Zhang, B., and Chen, J. (2016). A review on the application of metabonomic approaches in environmental toxicology. Asian J. Ecotoxicol. 11, 26-35. doi: 10.7524/AJE.1673-5897.20160118001

Golet, E. M., Xifra, I., Siegrist, H., Alder, A. C., and Giger, W. (2003). Environmental exposure assessment of fluoroquinolone antibacterial agents from sewage to soil. Environ. Sci. Technol. 37, 3243-3249. doi: 10.1021/ es0264448

Gusarov, I., Shatalin, K., Starodubtseva, M., and Nudler, E. (2009). Endogenous nitric oxide protects bacteria against a wide spectrum of antibiotics. Science 325, 1380-1384. doi: 10.1126/science.1175439

Holmes, E., Want, E. J., Wilson, I. D., Plumb, R. S., Shockcor, J., Nicholson, J. K., et al. (2010). Global metabolic profiling procedures for urine using UPLC-MS. Nat. Protoc. 5, 1005-1018. doi: 10.1038/nprot.2010.50

Hongguang, G., Naiyun, G., Ying, Y., and Yongli, Z. (2016). Kinetics and transformation pathways on oxidation of fluoroquinolones with thermally activated persulfate. Chem. Eng. J. 292, 89-91. doi: 10.1016/j.cej.2016.01.009

Hort, J. G., Krieg, N. R., Sneath, P. H. A., Stanley, J. T., William, S. T., et al. (1994). Bergey's Manual Of Determinative Bacteriology 9 Edition. Baltimore, MD: The William's \& Wilkins Co. doi: 10.1002/jps.3030470235

Hu, W., Huang, Y., Loka, D. A., Bai, H., Liu, Y., Wang, S., et al. (2020). Droughtinduced disturbance of carbohydrate metabolism in anthers and male abortion of two Gossypium hirsutum cultivars differing in drought tolerance. Plant Cell Rep. 39, 195-206. doi: 10.1007/s00299-019-02483-1

Karthikeyan, K. G., and Meyer, M. T. (2006). Occurrence of antibiotics in wastewater treatment facilities in Wisconsin, USA. Sci. Total Environ. 361, 196-207. doi: 10.1016/j.scitotenv.2005.06.030

Kosová, K., Vítámvás, P., Urban, M. O., Prášil, I. T., and Renaut, J. (2018). Plant abiotic stress proteomics: the major factors determining alterations in cellular proteome. Front. Plant Sci. 9:122. doi: 10.3389/fpls.2018.00122

Li, B., and Zhang, T. (2010). Biodegradation and adsorption of antibiotics in the activated sludge process. Environ. Sci. Technol. 44, 3468-3473. doi: 10.1021/ es $903490 \mathrm{~h}$

Li, X., Yao, S., Bian, Y., Jiang, X., and Song, Y. (2020). The combination of biochar and plant roots improves soil bacterial adaptation to PAH stress: insights from soil enzymes, microbiome, and metabolome. J. Hazard. Mater. 400:123227. doi: 10.1016/j.jhazmat.2020.123227

Liu, S., Fang, S., Xiang, Z., Chen, X., Song, Y., Chen, C., et al. (2021). Combined effect of microplastics and DDT on microbial growth: a bacteriological and metabolomics investigation in Escherichia coli. J. Hazard. Mater. 407:124849. doi: 10.1016/j.jhazmat.2020.124849

Liu, Y., Li, Z., Feng, Y., and Zhang, W. (2016). Research progress on microbial degradation of antibiotics. [Research progress on microbial degradation of antibiotics]. J. Agric. Environ. Sci. 35, 212-224. doi: 10.11654/jaes.2016.02.002

Liyanage, G. Y., and Manage, P. M. (2018). Removal of Ciprofloxacin (CIP) by bacteria isolated from hospital effluent water and identification of degradation pathways. IJMPD 2, 37-47. doi: 10.22161/ijmpd.2.3.1
Lu, J., Xu, R., and Li, Y. (2018). Clonostachys rosea SWFUYHL 02-03 infecting the body wall of Cephalcia chuxiongica larvae. [Clonostachys rosea SWFUYHL 0203 infecting the body wall of Cephalcia chuxiongica larvae]. J. Beijing For. Univ. $40,68-75$.

Maki, T. K. U. J., Hasegawa, H., Kitami, H., Fumoto, K., Munekage, Y., and Ueda, K. (2006). Bacterial degradation of antibiotic residues in marine fish farm sediments of Uranouchi Bay [Japan] and phylogenetic analysis of antibioticdegrading bacteria using 16 S rDNA sequences. Fish. Sci. 72, 811-820. doi: 10.1111/j.1444-2906.2006.01222.x

Prieto, A., Möder, M., Rodil, R., Adrian, L., and Marco-Urrea, E. (2011). Degradation of the antibiotics norfloxacin and ciprofloxacin by a white-rot fungus and identification of degradation products. Bioresour. Technol. 102, 10987-10995. doi: 10.1016/j.biortech.2011. 08.055

Reis, A. C., Kolvenbach, B. A., Nunes, O. C., and Corvini, P. F. X. (2020). Biodegradation of antibiotics: the new resistance determinants part II. New Biotechnol. 54, 13-27. doi: 10.1016/j.nbt.2019. 08.003

Reis, P. J. M., Reis, A. C., Ricken, B., Kolvenbach, B. A., Manaia, C. M., Corvini, P. F. X., et al. (2014). Biodegradation of sulfamethoxazole and other sulfonamides by achromobacter denitrificans PR1. J. Hazard. Mater. 280, 741749. doi: $10.1016 /$ j.jhazmat.2014.08.039

Sangster, T., Major, H., Plumb, R., Wilson, A. J., and Wilson, I. D. (2006). A pragmatic and readily implemented quality control strategy for HPLC-MS and GC-MS-based metabonomic analysis. Analyst 131, 1075-1078. doi: 10.1039/ b604498k

Schulz, J., Kemper, N., Hartung, J., Janusch, F., Mohring, S. A. I., and Hamscher, G. (2019). Analysis of fluoroquinolones in dusts from intensive livestock farming and the co-occurrence of fluoroquinolone-resistant Escherichia coli. Sci. Rep. 9:5117. doi: 10.1038/s41598-019-41528-z

Shatalin, K., Shatalina, E., Mironov, A., and Nudler, E. (2011). H2S: a universal defense against antibiotics in bacteria. [Journal Article. Research Support, N.I.H., Extramural; Research Support, Non-U.S. Gov't]. Science 334, 986-990. doi: $10.1126 /$ science. 1209855

Wang, Q. (2020). Characteristics And Risk Assessment Of Seven Typical Antibiotic Residues In Fish Pond From Lingui District,Guilin. Master's Thesis, Guilin university of technology. Available online at: Retrieved from https://kns.cnki.net $/ \mathrm{kcms} /$ detail/detail.aspx?FileName=1020389135.nh\& DbName=CMFD2021 Available from CNKI. (accessed June, 2021).

Wang, Q. (2021). Researches On The Metabolic Pathways Of Sulfonamides By Vibrio Diabolicus Strain L2-2 And Aeromonas Caviae Strain Glb-10 And Their Metabolizing Mechanisms. University of Chinese Academy of Sciences. Available online at: Retrieved from https://kns.cnki.net/kcms/detail/detail. aspx ?FileName=1021695193.nh\&DbName=CDFDTEMP Available from. (accessed September, 2021).

Wang, W., Li, T., Li, J., Liu, Q., and Xie, Y. (2012). HPLC-MS identification of degradation products of levofloxacin. [HPLC-MS identification of degradation products of levofloxacin]. Acta Pharm. Sin. 47, 498-501. doi: 10.16438/j.05134870.2012.04.020

$\mathrm{Xu}, \mathrm{Y}$., Yu, W., Ma, Q., and Zhou, H. (2015). Occurrence of (fluoro)quinolones and (fluoro)quinolone resistance in soil receiving swine manure for 11 years. Sci. Total Environ. 53, 191-197. doi: 10.1016/j.scitotenv.2015. 04.046

Yang, Y., Song, W., Lin, H., Wang, W., Du, L., and Xing, W. (2018). Antibiotics and antibiotic resistance genes in global lakes: a review and meta-analysis. Environ. Int. 116, 60-73. doi: 10.1016/j.envint.2018.04.011

Zhang, Y. (2017). Study On The Effects Of Various Cofactors On The Biodegradation Of Sulfamethoxazole by Alcaligenes faecalis. Master's Thesis, Tianjin University. Available online at: Retrieved from https://kns.cnki.net/kcms/detail/detail. aspx?FileName $=1018014228$. nh\&DbName $=$ CMFD2019 Available from CNKI. (accessed September, 2021).

Zhang, Z., Yu, Q., Zeng, X., Han, Z., Sun, D., and Muhammad-Aadil, R. (2015). Effects of pulsed electric field on selected properties of L-tryptophan. Int. J. Food Sci. Technol. 50, 1130-1136. doi: 10.1111/ijfs. 12758

Zhao, S., Liu, X., Cheng, D., Liu, G., Liang, B., Cui, B., et al. (2016). Temporalspatial variation and partitioning prediction of antibiotics in surface water and sediments from the intertidal zones of the Yellow River Delta, China. Sci. Total Environ. 56, 1350-1358. doi: 10.1016/j.scitotenv.2016.06 
Zhao, W., Xu, W., Wang, Y., Peng, X., and Huang, K. (2011). Techniques for metabolomics and its application. [Techniques for Metabolomics and Its Application]. Biotechnol. Bull. 12, 57-64. doi: 10.13560/j.cnki.biotech.bull.1985. 2011.12.004

Zhao, X., Chen, H., Jin, Z., Li, L., Zhang, J., and Kong, X. (2018). GC-MS-based metabolomics analysis reveals L-aspartate enhances the antibiotic sensitivity of neomycin sulfate-resistant Aeromonas hydrophila. J. Fish Dis. 41, 1831-1841. doi: $10.1111 /$ jfd. 12894

Conflict of Interest: The authors declare that the research was conducted in the absence of any commercial or financial relationships that could be construed as a potential conflict of interest.
Publisher's Note: All claims expressed in this article are solely those of the authors and do not necessarily represent those of their affiliated organizations, or those of the publisher, the editors and the reviewers. Any product that may be evaluated in this article, or claim that may be made by its manufacturer, is not guaranteed or endorsed by the publisher.

Copyright (c) 2022 Zhang, Sha, Li, Tang, Peng and Zhao. This is an open-access article distributed under the terms of the Creative Commons Attribution License (CC BY). The use, distribution or reproduction in other forums is permitted, provided the original author(s) and the copyright owner(s) are credited and that the original publication in this journal is cited, in accordance with accepted academic practice. No use, distribution or reproduction is permitted which does not comply with these terms. 